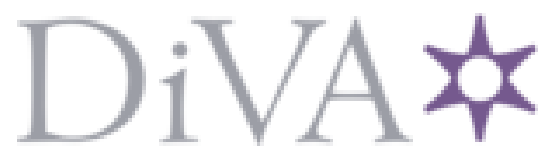

http://www.diva-portal.org

This is [Version unknown!] version of a paper published in Qualitative Health Research.

Citation for the original published paper (version of record):

Håkanson, C., Sahlberg-Blom, E., Ternestedt, B-M. (2010)

Being in the Patient Position: Experiences of Health Care Among People With Irritable Bowel Syndrome.

Qualitative Health Research

https://doi.org/10.1177/1049732310369914

Access to the published version may require subscription.

N.B. When citing this work, cite the original published paper.

Permanent link to this version:

http://urn.kb.se/resolve?urn=urn:nbn:se:oru:diva-10776 


\title{
Being in the Patient Position: Experiences of Health Care Among People With Irritable Bowel Syndrome
}

\author{
Cecilia Håkanson,' Eva Sahlberg-Blom, ${ }^{2}$ \\ and Britt-Marie Ternestedt ${ }^{3}$
}

\begin{abstract}
The purpose of this study was to gain in-depth understanding of what it is like for a person with irritable bowel syndrome to be in the patient position in encounters with health care providers. We conducted qualitative interviews with nine individuals. Our analysis, guided by interpretive description, revealed experiences of unsupportive and supportive encounters. Unsupportive encounters were shaped by humiliation, insignificance, and abandonment. Not feeling believed and acknowledged as persons made the participants lose trust in their own experience, which enhanced their unfamiliar mood of being in the world. Supportive encounters were less prominent. These were characterized by openness and acknowledgment of the patient's lifeworld. Feeling significant and being listened to promoted feelings of being in a partnered, cocreating relationship. It is reasonable to assume that care originating in the patient's lifeworld would support the patients to use their strength to manage illness and regain familiarity in everyday life.
\end{abstract}

\section{Keywords}

chronic illness; embodiment; health care, culture of; holistic care; lived experience; relationships

Irritable bowel syndrome (IBS) is one of the most frequently recognized conditions in patients consulting in general practice as well as gastroenterology (Delvaux, 2003; Drossman, Camilleri, Mayer, \& Whitehead, 2002). It is a chronic functional bowel disease that affects approximately $10 \%$ to $20 \%$ of the world's adult population, and is predominantly seen in women (Drossman et al., 2002; Longstreth et al., 2006). A person with IBS is typically troubled by abdominal pain or discomfort and altered bowel movements (diarrhea, constipation, or a mixture of both). Along with this, there are several other common problems such as flatulence, bloating, urgency to defecate, a sense of incomplete evacuation of the bowel, early satiety, and sometimes nausea (Drossman et al., 2002; Longstreth et al., 2006).

IBS is one of several chronic diseases that do not manifest externally. In fact, a person with IBS often appears well. However, living with IBS can be a struggle, living within an unpredictable body that offers unexpected expressions of illness when least desirable. For the ill person, these troubles are often experienced as bringing about shame and embarrassment in relation to others (Hakanson, SahlbergBlom, Nyhlin, \& Ternestedt, 2009). Everyday activities such as working, traveling, and socializing are often described as being limited because of ill health
(Bertram, Kurland, Lydick, Locke, \& Yawn, 2001; Dancey \& Backhouse, 1993; Fletcher, Jamieson, Schneider, \& Harry, 2008; Hakanson et al., 2009; Meadows, Lackner, \& Belic, 1997; Schneider \& Fletcher, 2008). The uncertainty of the body can negatively influence the individual's self-image, which along with physical symptoms contributes to limitations in everyday life (Hakanson et al., 2009; Ronnevig, Vandvik, \& Bergbom, 2009).

Within a holistic lifeworld perspective the patient is regarded as a whole, existential human being (Dahlberg \& Drew 1997). From this perspective, illness can be interpreted as a disruption of a person's lifeworld, replacing the taken-for-granted mood of the lived body with increased awareness of and unfamiliarity with the broken body (Toombs, 1988). Our lived experience is always colored by mood. Mood is perceptual, interactive, and intimately connected to how we find ourselves in the world,

\footnotetext{
'Karolinska Institute, Stockholm, Sweden

${ }^{2}$ Örebro University, Örebro, Sweden

${ }^{3}$ Ersta Sköndal University College, Stockholm, Sweden

Corresponding Author:

Cecilia Håkanson, Ersta Hospital, P. O Box 4622, SE-I I 6 9|

Stockholm, Sweden

Email: cecilia.hakanson@erstadiakoni.se
} 
and is therefore a powerful messenger of the meaning of our situation. Thus, emotional attunement is inseparable from the lifeworld. In health as well as in illness, mood as a qualitative dimension is part of a holistic understanding (Todres, Galvin, \& Dahlberg, 2007).

Svenaeus (2000a; see also Svenaeus 2000b, 2000c) built further on the work of Heidegger (2006) and Gadamer (1993) in the development of a phenomenological theory of health and illness to explain how being ill is essentially characterized as a state of unhomelikeness in which we are alienated from the way we feel at home in our bodies. According to Svenaeus (2000a), health, as opposed to illness, is a nonapparent attunement. It is a rhythmic, balancing mood that supports our individual understanding of the world in a homelike, taken-for-granted way. The balance of health refers to the natural way human beings find their place in the world of intersubjective meaning; a way of being in the world. However, the familiarity of our lifeworld is always in some way pervaded by homelessness. This homelessness is a basic and necessary condition of human existence, related to our finitude and dependence on others and otherness. We are in a world that we cannot entirely control. Health is thus to be understood as a being-at-home that keeps the not-being-athome in the world from becoming apparent. When we are ill, the meaning patterns of our being in the world are fractured. Our basic homelessness is stressed by illness, and thus brought to attention. The mood of illness manifests itself in prominent ways that color our whole existence and understanding. This is not an immediate experience, but a gradual transformation of the healthy homelike attunement into an unhomelike mood of illness (Svenaeus, 2000a). In the context of health care, this perspective is important to recognize because it enriches our understanding of the existential nature of illness, being the foundation for an ill person who encounters the health care system during his or her illness trajectory.

Encounters between health care providers and people with IBS can be sporadic or ongoing, and might involve several primary and/or specialist care providers. Even though there has been some movement toward a more multidisciplinary approach to care for this group of patients, the physician is still most commonly the main caregiver (Vandvik, Lydersen, \& Farup, 2006). Most of the chronic disease management in general, however, is conducted by the ill persons themselves, in the context of their everyday lives. Encounters between chronically ill patients and their health care providers are thus critically important opportunities for information exchange, decision making, and moral support (Thorne, Harris, Mahoney, Con, \& McGuinness, 2004).

There is substantial evidence in the literature that people with chronic diseases experience difficulties when they take on the role of patient (Thorne, 2006). The patient perspective of health care in relation to IBS has previously been given only limited attention. The few studies performed have described experiences of insufficient provision of information about the disease and treatment options, as well as experiences of being met with a lack of understanding and empathy and feelings of not being taken seriously by health care professionals (Bertram et al., 2001; Dancey \& Backhouse, 1993; Meadows et al., 1997). In the study by Meadows et al. (1997), teamwork between patient and physician was described by the study participants as being crucial for the outcome of the encounters.

Despite being few in number, these studies provide important insights about the topic, but they also raise further questions. None of them had a primary aim of exploring people's experiences of health care in relation to IBS. This means that experiences of health care were only briefly addressed in the articles. Furthermore, because the authors placed the emphasis on the participants' views from a symptom-oriented perspective, the articles do not offer a holistic, existential understanding about the topic. To achieve the desired goal of providing health care that promotes health and well-being, and supports the individuals in managing their disease in everyday life, we need to better understand what it can be like to encounter health care providers for IBS problems, from the perspective of those who have the experience. The aim of the present study was thus to deepen our understanding of what it is like for a person with IBS to be in the patient position in encounters with health care providers.

\section{Methods}

\section{Setting and Participants}

This study is the second of two studies performed to explore the lived experience of IBS in relation to everyday life and health care (Hakanson et al., 2009). Nine people (two men, seven women) were consecutively included in the study from a gastroenterology outpatient clinic in a Swedish hospital. The participants were all on a waiting list for a group-based patient education program. For the purpose of gaining rich descriptions, we sought individuals with a long illness trajectory (IBS diagnosis $>3$ years prior) who had multiple experiences of encountering various health care providers for IBS problems and were willing to share their stories (Morse, 2000; see also Thorne, 2008). For methodological reasons, we also wanted participants who could speak and understand Swedish with no interpretive assistance. The number of participants was regarded as an appropriate 


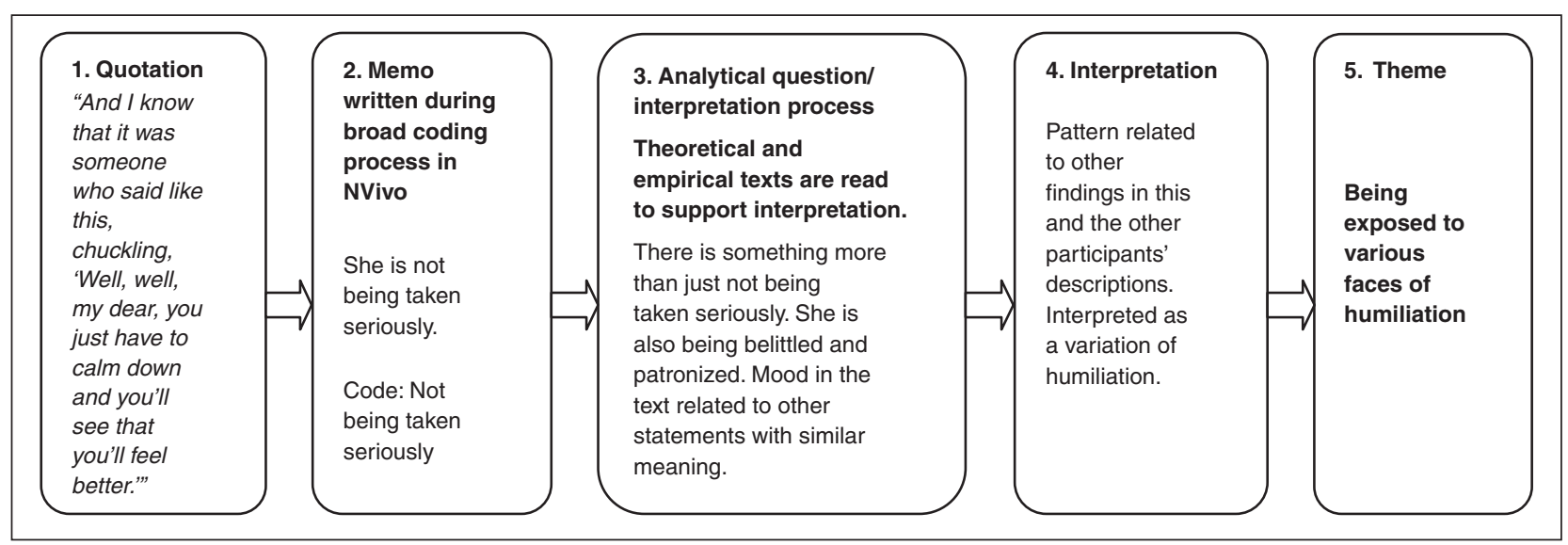

Figure I. Illustration of the analytical process

sample size to get a meaningful description of the phenomenon of interest (Thorne, 2008).

The participating individuals were aged between 25 and 48 years. Their health care consumption had varied over the years, but they all had a long history of seeking help for their IBS problems. They were all diagnosed with IBS more than 3 years prior to the interviews. All participants had academic degrees and were in full-time or part-time employment, with the sole exception of one woman who was on long-term sick leave.

\section{Data Collection}

Qualitative interviews were conducted in 2006. Each participant was interviewed twice, to capture the two different areas of interest for both studies. The second interview, representing the data collection for this study, was conducted 1 to 4 weeks after the first interview. The opening question for the interview was, "Can you tell me about your experiences of encounters with health care in relation to your IBS problems?" To promote concrete and rich descriptions, participants were asked follow-up questions such as, "What did you think or do then?" and "Can you tell me more about it?" Follow-up questions were also used to cover the areas of interest for the study: experiences of treatment, attitudes, and knowledge among health care professionals; experiences of participation in one's own health care; experiences of information and support; and experiences of being diagnosed. The study participants were informed orally and in writing about the purpose of the interview, both at the time of the study invitation and at the time of interview. The interviews were carried out in a quiet environment to ensure comfort and privacy. All interviews were performed by the first author. Each interview ended with a short summary of the main content of the interview. The summary was made by the researcher with the purpose of giving the participants the opportunity to add further information about issues that were brought up during the interview - if they felt something was missed or not fully clarified. The interviews lasted between 45 and 75 minutes, and were recorded and transcribed verbatim.

\section{Analysis}

Data analysis was carried out primarily by the first author in collaboration with the second and third authors. Interpretive description (Thorne, 2008; see also Thorne, Reimer Kirkham, \& MacDonald-Emes, 1997; Thorne, Reimer Kirkham, \& O'Flynn-Magee, 2004) was used to generate variations of themes based on differences and similarities in the data, through a process of inductive analysis. The purpose of interpretive description is to generate knowledge of practical importance to the applied disciplines. The approach is inspired by the systematic ideas of phenomenology, grounded theory, and ethnography. However, the idea is to let the nature of the data guide the choice of suitable analytical methods, rather than being constrained by one specific method. With interpretive description, previous empirical and theoretical knowledge is considered a preparatory structure for a new inquiry (Thorne, 2008).

The analysis (illustrated in Figure 1) proceeded according to the following steps: First, the interviews were listened to and the transcriptions were read several times to get a sense of the whole. Each text was organized and coded broadly, guided by analytic questions, thoughts, and possibly premature interpretations. The NVivo 8 computer software package (Bazeley, 2007) was used to assist with this early stage of data organization. 
According to Thorne (2008), trying to apprehend the overall picture will stimulate more coherent analytic frameworks for interpretive description than will sorting, filing, and combining vast quantities of small data units. During the process of organizing and coding data, analytic notes were written as comments or questions. The process of interpreting the data and identifying the core findings, themes, variations, and relationships in and between the themes was a continuous one. Once all texts were organized, this process involved moving back and forth between the coded data, the analytic notes, and relevant theoretical and empirical literature (Thorne, 2008). In the discussion of the findings, Svenaeus's (2000a) phenomenological theory of health and illness and the concept of unhomelikeness provided a theoretical understanding of the existential perspective on being a patient in a patienthealth care provider relationship.

Verification strategies for the purpose of ensuring rigor (Morse, Barrett, Mayan, Olson, \& Spiers, 2002) were built into the whole research process through our continuous theoretical knowledge development and guidance by senior researchers on issues concerning sampling, data collection, and choice of analytical method and theoretical perspective. The findings were repeatedly critically discussed among and validated by us and other research colleagues.

\section{Ethical Considerations}

Approval to conduct the study was granted by the research ethics committee of the Karolinska Institute, Stockholm. Interview studies of matters that might be associated with strong emotions for the individual participant can result in ethical conflicts between the knowledge desired by the researcher and possible harm to the participant. The provision of oral and written information regarding the study to potential subjects and emphasizing the voluntary aspect of participation gives some protection against this. In this study, an independent research nurse invited the participants by telephone. This was to protect the individuals from feeling awkward about declining to participate in the study if they wished to. Those who were interested in participating were sent written information about the study and a form to give written consent. At the time of inclusion and again at the time of interview, each person was informed orally about the right to withdraw from the study at any time without having to present a reason. This was also included in the written information. The participants were informed that all personal particulars would be removed from the data during the process of transcription.

The method we chose promoted free choice on the part of the participants as to what to talk about in the interviews. If the researcher reveals himself or herself as being genuinely interested in what the interviewees have to say, the interview might become an affirmative dialogue which is actually beneficial to the subjects, by allowing them to share personal experiences of living with an illness. Because we aimed to increase our previously limited knowledge of what it is like to be in the patient position in health care encounters, from the perspective of the patients, the benefits were considered to outbalance the potential risk of harm to the participants. The participants were also informed about the possibility of later contacting the IBS team at the hospital where the interviews were conducted if they wished to talk about matters that had been brought up during the interviews.

\section{Findings}

The study revealed two oppositional core positions, representing the study participants' experiences of being in the patient position in relation to their encounters with health care. The first position, "experiencing unsupportive encounters," included three themes comprising a variety of experiences shaped by humiliation, insignificance, and abandonment. The nature of these experiences seemed to influence the participants' self-trust as well as their ability to trust the health care system in the long run and to manage living with illness in the context of everyday life. The second and less prominent core position, "experiencing supportive encounters," can be viewed as an oppositional state. This position included one theme, "being acknowledged as a person," which represents experiences that were shaped by mutuality, understanding, and acknowledgment of the person's lived experience of illness. These encounters seemed to be the ones with the potential of assisting the participants on their path toward regaining familiarity and well-being in life. The themes are presented independently, with the two core positions used as headings.

The study participants' descriptions contained experiences from various health care providers and professions. They all had experiences from primary care as well as specialist care settings and emergency care. As expected, because of the organization of health care for people with IBS mentioned previously, there was an overemphasis on experiences of encounters with physicians. However, the participants mostly described their experiences of encounters from an overall perspective of health care, which made it difficult to distinguish between different types of health care providers or specific professions. Thus, the findings are presented with a focus on health care as a context and the meaning of the participants' experiences of encounters within this context, rather than giving specific professions too much attention. 
In the text, fictitious names have been used to personify the findings somewhat. All quotations were translated by a professional translator to minimize the risk of mistranslation and distortion of the meaning (Morse \& Richards, 2002).

\section{Experiencing Unsupportive Encounters}

Being exposed to various faces of humiliation. For the study participants, being in the patient position meant being exposed to various faces of humiliation. Not being taken seriously was one typical issue experienced. According to the participants, this was demonstrated by health care professionals dismissing their illness experiences through the use of patronizing or ill-considered statements: for example, telling them to calm down or to stop being hysterical about their symptoms. Joanna, a 42-year-old woman who had been heavily troubled by abdominal pain and constipation for several years, said,

It has happened sometimes when I have been really bad, that I have gone to some . . . care center. And I know there was someone who said, chuckling a bit, "Well, my dear, you just have to see to it that you calm down, then you'll see that you'll feel better."

The participants described having to struggle with their own experience of illness, as compared to the way they believed they were regarded by health care professionals. They described feeling accused of exaggerating or even imagining their illness, because there were no signs of disease, so their experiences were dismissed as irrelevant or nonexistent. The participants felt that looking ill would have been beneficial, because visible proof of illness would have provided affirmation and legitimacy for help seeking, and hence strengthened their positions in relation to the health care professionals.

Symptom fluctuation, which is typical in IBS, was a common source of humiliation among the study participants. The fact that symptoms could be obtrusively present on one day, and gone on the next, put them in awkward situations where they ended up justifying themselves to health care professionals, who they believed failed to take them seriously. Some of the participants had even felt the need to apologize for seeking help. Jane, a woman in her late 40 s who was troubled mainly by bloating and abdominal pain, had been struggling to get help for her IBS problems for a long time. She claimed that in some ways she could understand how hard it must be for the physicians she encountered to take her seriously, because her symptoms tended to fluctuate so much. She also described how her awareness of illness was suppressed during her good days:
Well, there wasn't really anyone who took that very seriously, and it's rather difficult because it comes and goes ... and when you get to the doctor then you might feel fine, then you might not even remember how it feels when you don't feel good.

The study participants often took the blame for health care visits that turned out to be unhelpful because the body stayed silent. Susanna, a woman in her 30s, had on several occasions turned to health care providers for help because of her constipation problems:

I went to the district medical officer or to the emergency ward because I was so constipated that I couldn't move and felt completely sick. Then they gave me a micro enema but nothing came out. "No, but then you must have emptied your bowels" [Susanna quotes a health care professional]. Like, then you feel like this: Am I crazy in the head? That is how I feel. They really made me feel like I was crazy.

Susanna felt she was not believed by the health care professionals. In this situation, when her body failed her, she felt embarrassed and foolish and started to question her own illness experience. This way of transforming uncontrollable physical expressions of the body into embodied failures was expressed by all participants. Susanna's preexisting awareness of her body as malfunctioning and unfamiliar, brought about by the disease itself, was thus intensified. The feelings covering the various faces of being exposed to humiliation seemed to be brought about by the health care professionals' behaviors and attitudes. That is, the patients and their illness experiences were not experienced as being either respected or appreciated in health care encounters, and thus no mutual understanding was achieved.

Being insignificant as a person. Another salient theme in the study concerned the experience of feeling insignificant as a person in the encounters with health care. All participants described situations in which they had not felt recognized as unique individuals, particularly in relation to medical investigation procedures or when they were being given advice about the disease. However, the foremost experience of insignificance was feeling as if their lived experience of illness was neither requested nor of any significant value in the care situation. Lack of recognition was experienced by the informants as if their knowledge about their own bodies, health, and life situation neither mattered nor was utilized in the care provided to them. Joanna described how, although she believed she had a lot of experience and information about her illness trajectory that could have been useful in accomplishing a 
shared understanding of her situation in encounters with health care providers, no one seemed to be interested:

So I think it's a bit lax of the doctors not to ask about what other medicine you're taking. They never ask that. They don't know what I eat, do they, but I have told them. But, sort of, they never ask that.

The participants said that often when they spoke out about concerns or worries about their illness or a specific care situation - for example examination proceduresthere was no understanding of their feelings. Michael, a man in his mid 40s, had been troubled by abdominal pain and diarrhea for a long period of time. He described himself as normally being strongly against going on sick leave, because it made him identify more with his disease and he did not want to be seen as a diseased person. However, this period of ill health had made him physically exhausted. He therefore explained to a physician that he needed to be on sick leave for a while: "I was actually in a state where I couldn't work any more. I was done. And I tried to explain that, but they didn't understand." Michael felt misunderstood and treated as someone who was trying to exploit the situation. He felt that the physician made no effort to either become familiar with him and his moral values, or to understand what being ill meant for Michael's everyday life.

Mary, a woman in her mid 30s, described another situation exemplifying the feeling of being insignificant as a person. Despite fear almost to the point of panic, she finally found the courage to undergo an endoscopic procedure. She had previously discussed the possibility of being anaesthetized during this procedure; however, she was told that anesthesia was never used the first time and therefore it was not an option. At the time of the examination, Mary shared her feelings with the assisting nurse and asked if she could at least have sedatives, as earlier recommended by her physician:

And I knew somehow it wasn't going to work out . . . well . . . yes, it simply turned out the way I expected, because it didn't work out when I got there. But I pepped myself up, and went in and said to the nurse that I wanted everything I could get. Then she said she thought that sounded exaggerated and that people exaggerate this so much. She'd done it several times, and it's not that hard, and it's so quick, and you just do it like this.

Mary felt that her lived experience of the procedure was of no interest to the health care professional in this situation. She felt as if her interpretation of the situation was trivialized and made not to matter by the health care professional's lack of openness and willingness to recognize her patient as a unique person. As Mary had expected, this meant that the endoscopic procedure could not be carried out, and she had to reschedule for a new endoscopy, this time with prearranged anesthesia.

We interpret the theme "being insignificant as a person" as covering feelings derived from encounters characterized by the absence of both intersubjectivity and openness toward the patients' experiences. The burden of illness is enhanced when the person behind the "patient" is not seen, not invited to share, and not allowed the weakness of being a help-seeking person with a lived experience.

Being abandoned by health care. This theme included experiences of being abandoned by health care providers in different ways. The participants believed that health care professionals regarded IBS patients as being of low priority because IBS was not a "real" disease. This was described as being particularly apparent in relation to the presentation of the diagnosis. Several of the participants had been told that in the absence of objective findings of serious diseases, the most plausible reason for their illness would be IBS. Mary said,

When I talked to the gastro doctor the first time when I had done the colonoscopy then. ... Well, but it feels a bit careless and it was like, "Yes, but this isn't anything big this ..." so, but you ... but it can be really hard, that it's not a real disease or sort of. ... Yes, that it wasn't really for real.

The participants experienced disinterest from the health care professionals in engaging with their illness once the medical inquiry was over. In most cases, the health care professionals did not initiate any follow-up visits or contacts. The participants experienced this as being "back to Square One," where they were before the time of the diagnosis, and left with no acknowledgment or practical support to assist in the process of regaining health and wellbeing in everyday life. This was described as a feeling of being abandoned with nowhere to turn. Caroline, a 28-yearold woman who talked a lot about the loneliness she had felt during her illness trajectory, recalled the encounter with the physician who gave her the diagnosis:

He was completely insensitive actually. He did say that it was irritable colon that I had, but then it was up to me. Meaning that I had to manage myself and figure out what to do with the problem. I felt totally abandoned then.

In most cases, the participants were not given sufficient information about the disease, the treatment options, or ways of managing the illness in everyday life. Little 
time was made available to sit down for a dialogue. The participants described having to struggle to get the attention of the health care professionals. Christopher, a man in his early 30 s who had struggled for years with painful diarrhea, shared his experience:

The doctors haven't taken any time. I have had to pull everything out of them that I need to know. They haven't sat down and really tried to explain and tried to encourage. They're absolutely no support. I don't know if it's a doctor's job, either, but I have really had to fight to get the information I have received.

The absence of dialogue and information was interpreted by the participants both as a lack of interest in engaging in their situation and as an avoidant behavior stemming from the physicians' lack of knowledge about IBS. Being abandoned by health care meant being left with no information about the disease and how to live with illness in everyday life. It also meant being left without continuous support and with the feeling of being a low priority in the health care system.

\section{Experiencing Supportive Encounters}

Being acknowledged as a person. Being acknowledged as a person was the least-prominent theme illuminated in the findings of this study. It illustrates the experience of being respected and recognized as a unique person with a lived experience of illness. That is, being listened to and feeling that the personal experience of illness was of significant importance in the encounter with health care providers. Susanna expressed her feelings about meeting a physician who finally believed her and took her problems seriously: "And then I was sort of touched to tears, because, God, someone's taking me seriously. I get so incredibly grateful that someone is actually ready to believe in me and devote time to me, it felt completely incredible."

One important issue of acknowledgment described by the study participants was the mutual trust that could be facilitated in an encounter when the health care professional attentively listened to and engaged in the patient's experience of his or her illness and life situation. Feeling significant and being listened to promoted feelings of active participation in the individual's own health care. Jennifer, a woman in her $40 \mathrm{~s}$, had been troubled by IBS problems since she was a young girl. She had gone through many devastating experiences of encounters with various health care providers before she met a physician who could provide her with the support she needed: "Just fantastic. Total trust in my family doctor, that is. He has a sort of confidence in my ability, at the same time as he understands that I am weak and need help."
Jennifer believed that this physician's interest in her lived experience of illness was the key to trust, rather than whether or not he had adequate knowledge about IBS. Coming to a specialist clinic where the health care professionals had a high degree of knowledge and experience about IBS, including how the disease might influence everyday life was, however, described by some of the participants as a great relief. This was because there was an immediate recognition of the disease itself, as well as an openness and interest in trying to understand the meaning of being ill to the individual. In this environment, the participants felt that they no longer had to defend or justify themselves: "It's so nice to be here. Here it doesn't feel like I need to defend myself” (Joanna).

Annie, a 41-year-old woman, had multiple experiences from emergency care settings because of her recurrent episodes of severe abdominal pain. For a long time, she kept being redirected to health care providers who were unable to help her. She talked about the contrast between her previous experiences of encounters with health care providers and what it was like when she was finally referred to a specialist clinic: "There was a huge difference in how you were received. Even when I have been relatively free of symptoms she [the doctor] performed a real checkup."

Being acknowledged also meant being provided legitimacy through diagnosis after a long illness trajectory, involving the struggle to get help from what the participants experienced as an insufficient health care delivery system. Most of the study participants experienced the diagnosis of IBS as providing a kind of legitimacy in relation to health care providers. Even though the diagnosis did not always help to increase the understanding of the disease, and did not automatically provide well-being, it was still described as a confirmation of the participants' illness experiences. To Caroline it was a relief to know that she had a disease that actually existed: "It doesn't feel like you're just someone who complains or is a bit hypochondriac or something, but you can actually say that it is something, you have a diagnosis for it."

We interpret the theme "being acknowledged as a person" as covering experiences of encounters where the attunement of the dialogue was trustful, and there was a mutual sharing of knowledge and understanding that helped participants feel that they were participating in the process of regaining familiarity and well-being by learning to manage their illness in everyday life.

\section{Discussion}

Our aim with this study was to deepen our understanding of what it is like for people with IBS to be in the patient position in encounters with health care providers. Two 
oppositional core positions emerged from the data. In most cases, the encounters with health care providers were experienced by the study participants as being unsupportive, and shaped by humiliation, insignificance, and abandonment. When medical examinations failed to show visible symptoms, the participants felt as though their bodily problems were being dismissed or defined as imaginary or exaggerated. When they did not feel believed and acknowledged as persons in the encounters, the participants lost trust in their own experiences. This attunement expressed by the participants is close to the mood of unhomelikeness described by Svenaeus (2000a). He pointed out that ill unhomelikeness of being in the world attains different meanings at different points of time for each individual. Living with IBS often means struggling with an everyday life that has gradually gone out of rhythm, as the lived body becomes unfamiliar and unreliable (Hakanson et al., 2009). For the participants in this study, the unhomelike mood of being in the world, initially brought about by their illness, was enhanced in the unsupportive encounters. Jingrot and Rosberg (2008) also reported analogous findings among people with exhaustion disorder as belonging to one of five stages within the gradual loss of homelikeness, entitled "loss of self-recognition."

In contrast to the unsupportive encounters, the participants also described occasional experiences of supportive encounters, characterized by respect and acknowledgment. The attunement of these encounters was trustful and appreciative of the lifeworld of the patient. The participants experienced that they were participating in their own care, while at the same time getting the knowledge and support they needed to gradually be able to transform their unhomelikeness into a more understandable homelike attunement in everyday life. The participants did not describe the two core positions as a process of going from unsupportive to supportive encounters, but rather as occasional comings and goings during their illness trajectory. One person could thus have experiences from both supportive and unsupportive encounters.

The two core positions illustrate how the nature and attunement of encounters with health care providers can influence the existential understanding of people with IBS in relation to their illness, in a way that either boosts or obstructs the feeling of homelikeness. Related but not transferable concepts have been used in previous studies about people with other chronic diseases to explicate the nature of patient-health care provider relationships. These concepts include empowerment and disempowerment, which have been studied in the context of women with chronic pain (Skuladottir \& Halldorsdottir, 2008), and connected relationships as opposed to disconnected relationships, described in a sample mainly represented by people with diabetes (Fox \& Chesla, 2008). Even if those concepts originated from different theoretical standpoints, and thus attained somewhat different meanings, they all point to the role of attunement and understanding in encounters between patients and health care professionals as being a crucial part of health care delivery in the chronic disease context.

Chronically ill patients are often described as viewing their diseases as defects, inadequacies, or shortcomings. Thus, encounters with health care providers always involve potentially humiliating physical and psychological exposure (Lazare, 1987). The patient is expected to reveal personal matters that are normally unspoken, and that are pervaded with unhomelikeness, to health care professionals who are often strangers, in unfamiliar health care environments. For a person with IBS, this becomes a matter of having to reveal bodily issues that are against social conventions to disclose. Shame in the context of illness, however, does not manifest only as shame about bodily dysfunctions or traits. It can also be an embodied experience of unhomelikeness, brought about by a negative evaluation of the self that is enhanced when the person does not feel as though he or she is being seen or believed (Skarderud, 2006). For the participants in this study, being exposed to humiliation, insignificance, and abandonment seemed to influence their selfevaluation. Even though none of our study participants explicitly used the word "shame" to describe their feelings, our interpretation is that experiences of embodied shame were present in relation to the encounters with health care professionals.

The participants experienced not being taken seriously and being disbelieved. These findings are coherent with previous work on the patient experience of IBS (Bertram et al., 2001; Dancey \& Backhouse, 1993; Meadows et al., 1997). The fluctuation of symptoms and the absence of visible signs of illness were experienced as contributing to the state of being called into question by health care professionals. The participants believed that visible biomedical evidence of disease would have enhanced their credibility as patients and thus strengthened their position in the encounters. This has also been shown in the context of other chronic diseases, such as fibromyalgia (Asbring \& Narvanen, 2002).

The study participants felt that their experiences of illness, the lived body, were subordinated or ignored in the encounters. They experienced their unhomelike attunement as one which remained unseen by the health care professionals. This implies that the participants' knowledge about their individual situations was not utilized in the encounters. Retention of patients' expertise is well described in relation to other chronic diseases (Asbring \& Narvanen, 2002; Henriksson, 1995; Paulson, Norberg, \& 
Danielson, 2002; Thorne, Ternulf Nyhlin, \& Paterson, 2000 ), but only briefly in relation to IBS (Bertram et al., 2001; Dancey \& Backhouse, 1993). From a lifeworld perspective, the body is regarded as a lived unity of mind, body, and world. A person is, and lives, through the body (Bullington, 2009). Within the biomedical paradigm, the traditional dualistic perspective of body and soul as separate units makes it difficult to understand the existential meaning of illness, which is well reflected in the descriptions of our study participants. Toombs (1987) pointed out that the health care professional and the patient occupy different horizons of meaning in the encounter. The world of the health care professional is primarily one of disease, whereas the patient's world is one of lived illness. Thus, the two parties acquire two different types of knowledge that are both essential in the encounter. The health care professional has the medical expertise and task to help the patient. The patient has the primary understanding about the mood of unhomelikeness which is the actual matter of the encounter (Svenaeus, 2000a). In a study about encounters between formal and informal care at the end of life, James, Andershed, and Ternestedt (2009) suggested that informal care performed by loved ones can be understood as a kind of practical knowledge, linked to Aristotle's phronesis, that is complementary to medical expertise. In the context of our study, the participants' lived experiences of IBS can be translated to practical knowledge. It is noticeable in our findings how the two different perspectives seemed to be incongruous rather than merging into some kind of shared understanding, mostly to the benefit of the biomedical interpretation of the situation.

The participants' feelings of being met with skepticism might have enhanced their own feelings of guilt about taking up the health care professional's time because of a body that had stayed silent at the time of the encounter. Werner and Malterud (2003) similarly described how women with chronic pain struggled to fit in with normative biomedical expectations by trying to appear credible in their encounters with health care providers. Thesen (2005) claimed that most acts of humiliation and dismissive attitudes toward patients in patient-physician relationships are unintended and unrecognized by the physicians themselves. It is likely that this is the case for other health care professionals as well. Nevertheless, power arises from the culture of the health care system, and therefore the health care professionals are the ones who define the rules in the encounters (Schei, 2006). The tendency toward reducing the patient to an object and putting the emphasis on specialization in health care has been discussed previously in other studies. Our participants' experiences of being objectified in their encounters with health care providers are in agreement with the findings of studies performed in other disease contexts (Arman, Rehnsfeldt, Lindholm, Hamrin, \& Eriksson, 2004).

Previous studies have shown that patients with IBS experience an insufficiency of information about the disease and about how to manage their illness in everyday life (Bertram et al., 2001; Dancey \& Backhouse, 1993). Our participants experienced lack of engagement, lack of sufficient information, and lack of follow-up procedures as feeling abandoned by the health care delivery system. This has also been described among people with fibromyalgia (Haugli, Strand, \& Finset, 2004) and rheumatic disease (Paulson et al., 2002). Our study participants described being given too little information to be able to manage the illness in their everyday lives. They were offered few chances to talk about the meaning of the diagnosis to them and their life situation. They felt they had been left with no acknowledgment or support to assist in the process of regaining homelikeness in everyday life. Patients with multiple sclerosis have been described as experiencing the necessity of assuming full responsibility for the management of clinical as well as personal aspects of their disease for the same reasons, thus bringing about the same feelings as the participants in our study (Thorne, Con, McGuinness, McPherson, \& Harris, 2004).

Although they were few in number, supportive encounters were also described by the study participants. From the basis of a holistic lifeworld perspective, an encounter can be understood as an intersubjective and meaningful meeting in which acknowledgment and growth of the patient is of primary importance (Dahlberg \& Drew, 1997; Todres et al., 2007). In our study, being acknowledged was described by the study participants as being trusted and recognized as unique individuals with their own lived experiences. This was experienced as facilitating a mutual trust in encounters with health care professionals. Feeling significant and being listened to promoted feelings among the participants of being in a partnered, cocreating relationship. Similarly, in other disease contexts, validation of patients' illness experiences and the feeling of togetherness have been described as being very helpful in the process of learning to manage life with illness and regaining a more homelike attunement (Haugli et al., 2004; Thorne, Con, et al., 2004).

For the participants in our study, the experience of supportive encounters did not seem to be dependent only on the expert knowledge of the health care professionals, but also on their moral values and attitudes toward their patients. These findings are in agreement with the study by Meadows et al. (1997) mentioned earlier. However, some of the participants in our study described a feeling of ease when encountering health care providers with specialist knowledge about IBS, because there was an 
immediate recognition of the disease. In these encounters, the study participants felt that they did not have to defend or justify themselves. In addition, they received the information they needed to be able to manage their own care in the context of their everyday lives. Related findings have been reported in the context of breast cancer, with supportive care settings described as being characterized by an atmosphere of ease that facilitated locating oneself in familiar and safe surroundings, and in being seen, acknowledged, and cared about (Edvardsson, Sandman, $\&$ Rasmussen, 2005). The study participants experienced the diagnosis of IBS as providing a kind of legitimacy in relation to health care providers. It also meant that they could start to trust their own illness experiences. Thus, the diagnosis to some extent helped to make the body understandable and helped them to recognize themselves in the world again. Fox and Chesla (2008) presented similar findings.

A need for help is the most common reason for an encounter between a patient and a health care professional. The patient is the help seeker, and the health care professional is there to help the patient (Svenaeus, 2000c). In this study, the participants generally did not believe they received the support they needed. Because IBS is a chronic disease, according to Svenaeus (2000a) the goal of changing the present unhomelikeness of the patient's being in the world into something more homelike is even more dependent on the health care professional getting to know the patient's life situation. The objective body of a person with IBS will continue to malfunction, but on the level of the lifeworld, which is the experienced level lived by the patient, the unhomelikeness can be restrained and the balance in life can become less out of rhythm. To regain homelike attunement, the patient needs help to change his or her understanding of the situation.

Optimal quality of data is ensured by an appropriate sampling of participants that best represents the research topic (Thorne, 2008). The participants in our study had been troubled by IBS problems for many years and had wide-ranging experiences of encounters within multiple health care settings. It is worth mentioning that all participants were well educated; it is not clear whether this in any way influenced their experiences or the way they described these experiences in the interviews. We believe that although the sample was small, the study findings provide knowledge that helps to enrich our understanding of what it can be like to be in the patient position in relation to health care in the context of IBS.

\section{Conclusions and Implications for Health Care}

The study findings illuminate the need for recognition of the patient's lifeworld. It is indisputably important on all health care levels that health care professionals be knowledgeable about IBS to facilitate the provision of appropriate information to patients about the disease itself, as well as how to manage in everyday life. The most important issue, however, seems to be the need for a transformation of health care in a direction that strengthens the patient's position and also takes into consideration the lived experience of illness in a way that counteracts the reduction of the patient to an object. This might seem easier said than done, and it is important to recognize the factors within the current health care delivery system that might obstruct this process. Thorne (2006) argued that much of what underpins the attitudinal problem is the predominance of the acute care model that dominates most health care levels and settings where people with chronic diseases are found. She claimed that the typical systems of diagnosis, referral, consultation, information access, and resource gatekeeping are all predicated on the assumption that the patient's health and well-being depend solely on the expertise and authority of the professional.

It is vital for there to be trustful and mutual dialogue about the meaning of being ill to the patient and his or her life situation, and an agreement on the roles that the patient and the health care provider will variously play in the process of regaining homelikeness for the patient. Possible ways of improving care include organizational changes such as allowing an appropriate length of time for encounters between patients with IBS and health care professionals - especially at the beginning of their illness trajectory and when the diagnosis is given - and increased availability of continuous telephone support, for example with IBS-competent nurses. By doing this, we can begin to become consultants positioned to support patients in finding solutions to manage their illness and regain homelikeness in life, while still encouraging them to use their own strength to become masters of their own lives. We suggest that it would be productive to conduct interventions that include education of patients as well as health care professionals about IBS, and to implement approaches to care based on the lifeworld perspective (Todres et al., 2007) and the phenomenological theory of health and illness (Svenaeus, 2000a).

\section{Acknowledgments}

We thank the study participants for generously sharing their experiences during the interviews.

\section{Declaration of Conflicting Interests}

The authors declared no conflicts of interest with respect to the authorship and/or publication of this article.

\section{Funding}

The authors disclosed receipt of the following financial support for the research and authorship of this article: The research was 
supported by funds received from Ersta Hospital, Stockholm, Sweden, and The Swedish Association of People with Stomach and Bowel Diseases.

\section{References}

Arman, M., Rehnsfeldt, A., Lindholm, L., Hamrin, E., \& Eriksson, K. (2004). Suffering related to health care: A study of breast cancer patients' experiences. International Journal of Nursing Practice, 10(6), 248-256.

Asbring, P., \& Narvanen, A. L. (2002). Women's experiences of stigma in relation to chronic fatigue syndrome and fibromyalgia. Qualitative Health Research, 12, 148-160.

Bazeley, P. (2007). Qualitative data analysis with Nvivo. London: Sage.

Bertram, S., Kurland, M., Lydick, E., Locke, G. R., III, \& Yawn, B. P. (2001). The patient's perspective of irritable bowel syndrome. Journal of Family Practice, 50(6), 521-525.

Bullington, J. (2009). Embodiment and chronic pain: Implications for rehabilitation practice. Health Care Analysis, 17(2), 100-109.

Dahlberg, K., \& Drew, N. (1997). A lifeworld paradigm for nursing research. Journal of Holistic Nursing, 15(3), 303-317.

Dancey, C. P., \& Backhouse, S. (1993). Toward a better understanding of patients with irritable bowel syndrome. Journal of Advanced Nursing, 18(9), 1443-1450.

Delvaux, M. (2003). Functional bowel disorders and irritable bowel syndrome in Europe. Alimentary Pharmacology \& Therpeutics, 18(Suppl. 3), 75-79.

Drossman, D. A., Camilleri, M., Mayer, E. A., \& Whitehead, W. E. (2002). AGA technical review on irritable bowel syndrome. Gastroenterology, 123(6), 2108-2131.

Edvardsson, J. D., Sandman, P. O., \& Rasmussen, B. H. (2005). Sensing an atmosphere of ease: A tentative theory of supportive care settings. Scandinavian Journal of Caring Sciences, 19(4), 344-353.

Fletcher, P. C., Jamieson, A. E., Schneider, M. A., \& Harry, R. J. (2008). "I know this is bad for me, but . . .": A qualitative investigation of women with irritable bowel syndrome and inflammatory bowel disease: Part II. Clinical Nurse Specialist, 22(4), 184-191.

Fox, S., \& Chesla, C. (2008). Living with chronic illness: A phenomenological study of the health effects of the patientprovider relationship. Journal of the American Academy of Nurse Practitioners, 20(3), 109-117.

Gadamer, H.-G. (1993). Über die verborgenheit der gesundheit [The enigma of health]. Frankfurt, Germany: Suhrkamp Verlag.

Hakanson, C., SahlbergBlom, E., Nyhlin, H., \& Ternestedt, B. M. (2009). Struggling with an unfamiliar and unreliable body: The experience of irritable bowel syndrome. Journal of Nursing and Healthcare of Chronic Illness, 1(1), 29-38.

Haugli, L., Strand, E., \& Finset, A. (2004). How do patients with rheumatic disease experience their relationship with their doctors? A qualitative study of experiences of stress and support in the doctor-patient relationship. Patient Education and Counseling, 52(2), 169-174.

Heidegger, M. (2006). Zen und zeit [Being and time] (16th ed.). Tübingen, Germany: Max Niemyer Verlag.

Henriksson, C. M. (1995). Living with continuous muscular pain. Patient perspectives. Part I: Encounters and consequences. Scandinavian Journal of Caring Sciences, 9(2), 67-76.

James, I., Andershed, B., \& Ternestedt, B. (2009). The encounter between informal and professional care at the end of life. Qualitative Health Research, 19, 258-271.

Jingrot, M., \& Rosberg, S. (2008). Gradual loss of homelikeness in exhaustion disorder. Qualitative Health Research, 18, 1511-1523.

Lazare, A. (1987). Shame and humiliation in the medical encounter. Archives of Internal Medicine, 147(9), 1653-1658.

Longstreth, G. F., Thompson, W. G., Chey, W. D., Houghton, L. A., Mearin, F., \& Spiller, R. C. (2006). Functional bowel disorders. Gastroenterology, 130(5), 1480-1491.

Meadows, L. M., Lackner, S., \& Belic, M. (1997). Irritable bowel syndrome. An exploration of the patient perspective. Clinical Nursing Research, 6(2), 156-170.

Morse, J. M. (2000). Researching illness and injury: Methodological considerations. Qualitative Health Research, 10, 538-546.

Morse, J. M., Barrett, M., Mayan, M., Olson, K., \& Spiers, J. (2002). Verification strategies for establishing reliability and validity in qualitative research. International Journal of Qualitative Methods, 1(2), 1-19.

Morse, J. M., \& Richards, L. (2002). Read me first for a user's guide to qualitative methods. Thousand Oaks, CA: Sage.

Paulson, M., Norberg, A., \& Danielson, E. (2002). Men living with fibromyalgia-type pain: Experiences as patients in the Swedish health care system. Journal of Advanced Nursing, 40(1), 87-95.

Ronnevig, M., Vandvik, P. O., \& Bergbom, I. (2009). Patients' experiences of living with irritable bowel syndrome. Journal of Advanced Nursing, 65(8), 1676-1685.

Schei, E. (2006). Skam i pasientrollen [Shame in the patient role]. In P. Gulbrandsen, P. Fugelli., G. H. Stang, \& B. Wilmar (Eds.), Skam $i$ det medisinske rom [Shame in the medicine room] (pp. 15-30). Oslo, Norway: Gyldendal Norsk Forlag AS.

Schneider, M. A., \& Fletcher, P. C. (2008). I feel as if my body is keeping me hostage! Exploring the negative impact of irritable bowel syndrome (IBS) and inflammatory bowel disease (IBD) on university-aged woman. International Journal of Nursing Practice, 14(2), 135-148.

Skarderud, F. (2006). Flukten til kroppen. Senmoderne skamfortellinger [The escape to the body. Postmodern stories of shame]. In P. Gulbrandsen, P. Fugelli., G. H. Stang, \& B. Wilmar (Eds.), Skam i det medisinske rom [Shame in the medicine room] (p. 64). Oslo, Norway: Gyldendal Norsk Forlag AS.

Skuladottir, H., \& Halldorsdottir, S. (2008). Women in chronic pain: Sense of control and encounters with health professionals. Qualitative Health Research, 18, 891-901. 
Svenaeus, F. (2000a). The hermeneutics of medicine and the phenomenology of health. Steps toward a philosophy of medical practice. Dordrecht, Netherlands: Kluwer Academic.

Svenaeus, F. (2000b). The body uncanny. Further steps toward a phenomenology of illness. Medicine, Health Care and Philosophy, 3(2), 125-137.

Svenaeus, F. (2000c). Das unheimliche. Toward a phenomenology of illness. Medicine, Health Care and Philosophy, 3(1), 3-16.

Thesen, J. (2005). From oppression toward empowerment in clinical practice. Offering doctors a model for reflection. Scandinavian Journal of Public Health, 33(Suppl. 66), 47-52.

Thorne, S. (2006). Patient-provider communication in chronic illness: A health promotion window of opportunity. Family \& Community Health, 29(Suppl. 1), 4-11.

Thorne, S., Con, A., McGuinness, L., McPherson, G., \& Harris, S. R. (2004). Health care communication issues in multiple sclerosis: An interpretive description. Qualitative Health Research, 14, 5-22.

Thorne, S., Reimer Kirkham, S., \& MacDonald-Emes, J. (1997). Interpretive description: A noncategorical qualitative alternative for developing nursing knowledge. Research in Nursing \& Health, 20(2), 169-177.

Thorne, S., Reimer Kirkham, S., \& O’Flynn-Magee, K. (2004). The analytic challenge in interpretive description. International Journal of Qualitative Methods, 3(1), 1-20.

Thorne, S., Ternulf Nyhlin, K., \& Paterson, B. L. (2000). Attitudes toward patient expertise in chronic illness. International Journal of Nursing Studies, 37(4), 303-311.

Thorne, S. E. (2008). Interpretive description. Walnut Creek, CA: Left Coast Press.

Thorne, S. E., Harris, S. R., Mahoney, K., Con, A., \& McGuinness, L. (2004). The context of health care communication in chronic illness. Patient Education and Counseling, 54(3), 299-306.
Todres, L., Galvin, K., \& Dahlberg, K. (2007). Lifeworld-led healthcare: Revisiting a humanising philosophy that integrates emerging trends. Medicine, Health Care \& Philosophy, 10(1), 53-63.

Toombs, S. K. (1987). The meaning of illness: A phenomenological approach to the patient-physician relationship. Journal of Medicine and Philosophy, 12(3), 219-240.

Toombs, S. K. (1988). Illness and the paradigm of lived body. Theoretical Medicine, 9(2), 201-226.

Vandvik, P. O., Lydersen, S., \& Farup, P. G. (2006). Prevalence, comorbidity and impact of irritable bowel syndrome in Norway. Scandinavian Journal of Gastroenterology, 41(6), 650-656

Werner, A., \& Malterud, K. (2003). It is hard work behaving as a credible patient: Encounters between women with chronic pain and their doctors. Social Science \& Medicine, 57(8), 1409-1419.

\section{Bios}

Cecilia Håkanson, RN, MSc, is a doctoral student in the Department of Neurobiology, Care Sciences and Society, Division of Nursing, at Karolinska University, Stockholm, Sweden, and head of care development at Ersta Hospital, Stockholm, Sweden.

Eva Sahlberg-Blom, RNT, PhD, is a lecturer in the School of Health and Medical Sciences at Örebro University, Örebro, Sweden, and a coordinator in the Department of Palliative Care Research at Ersta Sköndal University College, Stockholm, Sweden.

Britt-Marie Ternestedt, RNT, is a professor and director of the Department of Palliative Care Research at Ersta Sköndal University College, Stockholm, Sweden, and an affiliated professor in the Department of Neurobiology, Care Sciences and Society, Division of Nursing, at Karolinska University, Stockholm, Sweden. 